\title{
EDUCAÇÃO DE ADULTOS (EJA): Capital cultural e percepções sobre a escola na Amazônia amapaense
}

\author{
Adalberto Carvalho Ribeiro \\ Sirliane da Costa Viana
} Aldenise da Silva Rodrigues ${ }^{(*)}$

Propõe-se trabalhar neste artigo a contextualização da Educação de Jovens e Adultos (EJA), utilizando-se, principalmente, das seguintes categorias: percepção, capital cultural e camadas populares. Partindo-se do princípio que o aluno é o principal elemento que compõe essa modalidade de ensino, fez-se uma análise sobre o relato de suas rotinas, suas percepções e suas expectativas sobre o término da educação básica.

O artigo está dividido em cinco seções, além desta introdução e das aproximações conclusivas. Na segunda seção, o artigo conta com a abordagem metodológica apoiada no Materialismo Histórico Dialético, de Karl Marx, uma vez que se baseia na análise de uma modalidade de ensino que está inserida em um contexto de desigualdades e preconceitos.

$\mathrm{Na}$ seção seguinte, destaca-se um arcabouço teórico sobre a história da EJA no cenário brasileiro, sua inserção como política pública educacional e desafios que vem enfrentando para a concretização de seus objetivos. Discute-se a compreensão da EJA em vista da diversidade humana, ou seja, as individualidades de cada sujeito, pois fazem parte de uma sociedade marcada por heterogeneidades. Dessa forma, vale ressaltar que o aluno da EJA já possui um perfil traçado, no entanto, para além de identificar quem são esses alunos é reconhecer seus esforços em estar mais uma vez tentando estudar e potencializar suas disposições.

Na quarta seção, discute-se sobre o capital cultural das camadas populares e as influências que este exerce sobre o desenvolvimento educacional dos alunos investigados, as dificuldades enfrentadas em disciplinas específicas, as heranças familiares e as possibilidades de apoio nos estudos, bem como as expectativas de vida em razão de suas condições financeiras, culturais e materiais.

\footnotetext{
${ }^{(*)}$ Adalberto Carvalho Ribeiro. Professor de Sociologia da Educação na Universidade Federal do Amapá, pesquisador e doutor em Ciências: desenvolvimento socioambiental pelo Núcleo de Altos Estudos Amazônicos (NAEA/UFPA). Email: adalb.cr@gmail.com.

Sirliane da Costa Viana. Professora, pesquisadora e Mestre em Políticas Públicas pela UNIFAP. Leciona as disciplinas Educação de Jovens e Adultos e Movimentos Sociais e Educação. E-mail: sirliane1@gmail.com.

Aldenise da Silva Rodrigues. Geógrafa e Especialista em Política Educacional pela Universidade Federal do Amapá (UNIFAP). E-mail: denise @gmail.com.
} 
Na quinta seção, no estudo das percepções, analisa-se o olhar do aluno sobre o ensino da EJA, através de suas experiências de vida e como esses alunos dão importância à escola. Dessa forma, a percepção seria um mecanismo para a interpretação da realidade desses sujeitos.

Na sexta seção, mostram-se os achados de campo, apontando a influência do capital cultural sobre o aspecto educacional desses alunos, bem como a singularidade das percepções sobre escola e perspectiva em ingressar o ensino superior. Além disso, visualiza-se através do relato de suas rotinas a interpretação das dificuldades enfrentadas por um aluno de EJA buscando uma nova oportunidade através dos estudos.

\section{Abordagem metodológica}

Metodologicamente, a teoria utilizada foi o Materialismo Histórico Dialético porque revela as assimetrias da sociedade capitalista e das classes sociais. A utilização dessa abordagem se fez necessária considerando a realidade vivenciada por alunos da EJA, marcadamente com história de excluídos em um país capitalista nos moldes do Brasil.

De acordo com Sobral (2012, p.10), “[...] historicamente, foram as condições materiais da vida social que mediaram a formação do pensamento, da linguagem e da capacidade de produzir conhecimento dos sujeitos humanos [...]". O autor complementa ainda que o método dialético de Marx enxerga nas contradições históricas a chave para o entendimento dos fatos históricos, que são marcados por relações sociais.

$\mathrm{Na}$ abordagem procedimental/instrumental utilizamos o método estatístico e a análise de conteúdo uma vez que a pesquisa é quali-quantitativa. O método estatístico tem o mérito de utilizar os dados de forma mensurada e por percentuais. Já a análise de conteúdo analisa o discurso dos participantes, interpretando e levando em consideração cada informação coletada, pois elas têm um valor muito particular.

O ambiente da pesquisa se deu em uma escola pública, da cidade de Macapá-AP, Estado do Amapá localizado na região amazônica, na parte setentrional. Os sujeitos foram estudantes da segunda etapa da EJA em número de 70. Esta foi a quantidade de questionários semiestruturados com perguntas fechadas e questões abertas aplicados. Portanto, as abordagens quali-quantitativas caminham juntas na análise dos dados desta investigação. No âmbito educacional contribuem para contextualizar problemas poucos divulgados ou pouco debatidos. Segundo Gatti (2004, p.13),

[...] há problemas educacionais que para sua contextualização e compreensão necessitam ser qualificados através de dados quantitativos. Por exemplo, como compreender a questão do analfabetismo no Brasil, e discutir políticas em relação a esse problema [...]. As duas 
abordagens demandam, no entanto, o esforço de reflexão do pesquisador para dar sentido ao material levantado e analisado.

Gatti (2004) enfatiza ainda que "os métodos de análise de dados que se traduzem por números podem ser muito úteis na compreensão de diversos problemas educacionais". Optou-se dessa forma a importância de se trabalhar com essas duas análises, visto que são complementares uma para outra.

A referida investigação inferiu sobre as questões sociais e culturais que fazem parte da realidade dos alunos, especialmente no que se direciona à sua formação educacional; pautou ainda seus desafios, dificuldades e percepções sobre as possibilidades de futuro. $\mathrm{O}$ tratamento dos dados permitiu inferir também as opiniões sobre o contexto social e cultural desses indivíduos.

\section{APONTAMENTOS SOBRE A EJA NO BRASIL}

\section{Educação de Jovens e Adultos no cenário brasileiro: contradições e desafios}

A EJA no cenário das políticas públicas ainda se constitui em um grande desafio que vem sendo enfrentado ao longo dos anos, pois o reconhecimento desta modalidade de ensino caminha lentamente como um espaço de conquistas.

De acordo com Pierro, Joia e Ribeiro (2001, p.70)

[...] os objetivos da formação de pessoas jovens e adultas não se restringem à compensação da educação básica não adquirida no passado, mas visam a responder às múltiplas necessidades formativas que os indivíduos têm no presente e terão no futuro. Sendo tais necessidades múltiplas, diversas e cambiantes, as políticas de formação de pessoas adultas deverão ser necessariamente abrangentes, diversificadas e altamente flexíveis.

Pensar em políticas públicas pressupõe entender as relações que permeiam o seu desenvolvimento, os agentes envolvidos e sua importância. Diante disso, conforme Boneti (2012, p.18), "no estudo das Políticas Públicas, não se pode deixar de se considerar obviedade a relação entre classe social e Estado, no capitalismo, deve-se compreender as políticas públicas como um todo, entre as classes sociais e o Estado".

No caso da EJA, esta começou a ganhar espaço de fato na Constituição Federal de 1988 e com mais clareza e especificidade na Lei de Diretrizes e Bases - LDB (Lei 9.394/96), e desde então essa modalidade de ensino busca superar desigualdades de tratamento existentes nos sistemas educacionais.

Mesmo que a EJA venha ganhando espaço no meio educacional, ela não tem autonomia para seu pleno desenvolvimento, pois “[...] ainda é permeada por estigmas, preconceitos, nem sempre se 
configurando como uma educação de qualidade, permanecendo à margem dos processos de escolarização.” (NIENCHOTER; STEINDEL, 2013, p.14).

Uma grande problemática levantada nas políticas públicas para a "EJA", trata-se da maneira na qual ela vem sendo empregada, pois, sendo uma modalidade direcionada aos que não tiveram acesso ao ensino na idade apropriada e às classes menos favorecidas, convencionou-se decidir que seria um ensino não prioritário, apenas compensatório.

De acordo com Oliveira, Lima e Pinto (2012, p.197) “os discursos que enredaram a EJA nem sempre ou quase nunca se efetivaram na prática, essa forma, muito embora, as intenções legais "fossem boas", muito pouco se fez." $\mathrm{Na}$ atualidade ainda se caminha a passos lentos para sua efetivação.

Ademais, as políticas públicas educacionais brasileiras não são universais. As desigualdades econômicas e sociais afetam diretamente o setor da educação, uma vez que ela é o principal instrumento para que outros setores cresçam. Em vista disso, o que se observa no país são políticas públicas segmentadas que refletem ainda mais as desigualdades, no entanto, ainda que de modo precário, nos últimos anos, pode-se dizer que foram essas políticas que vem dando vez e vozes a parcelas da sociedade que não tinham acesso a seus direitos garantidos na Constituição.

Beisiegel (1997) discorre que a EJA veio para melhor preparar esses indivíduos à participação na vida social, isso incluiria, necessariamente, seu envolvimento na luta pela afirmação dos próprios direitos. No entanto, entende-se a EJA em um sentido contraditório, uma vez que suas finalidades não condizem com as práticas e realidades vivenciadas pelos alunos.

Ao se referir sobre a EJA no Brasil, não é novidade, já se tem um perfil formado dos sujeitos, que são, geralmente, trabalhadores, pessoas que não tiveram oportunidades na juventude. Conforme mencionam Oliveira, Lima e Pinto (2012, p.191), “[..] formam um grupo muito diversificado, que venceu barreiras para estar de volta à escola e que luta diariamente contra o cansaço e outros obstáculos de sua vida cotidiana."

Compreender a EJA, portanto, é dar lugar à diversidade humana em uma sociedade marcada por heterogeneidades, onde cada indivíduo possui suas particularidades. Para Pierro, Joia e Ribeiro (2001, p.74),

[...] os debates atuais sobre os objetivos da educação para a cidadania privilegiam a formação de sujeitos livres, autônomos, críticos, abertos à mudança, capazes de intervir em processos de produção cultural que tenham alcance político. 
Nesse sentido, para Duarte (2012, p.15), Paulo Freire “[...] coloca o ser humano como centro de todas as transformações, sociais, políticas e econômicas. [...] capaz de intervir, modificar e transformar seu entorno social, [...] capaz de sair de sua situação". Portanto, há no campo educacional inúmeras possibilidades para o processo de mudança na sociedade.

\section{CAPITAL CULTURAL DAS CAMADAS POPULARES: SUA IMPORTÂNCIA PARA O DESENVOLVIMENTO EDUCACIONAL}

Sobre uma lógica do capital cultural no contexto da educação, percebe-se claramente que este é produzido de acordo com as trajetórias familiares, ainda que este recurso também tenda a ser distribuído de maneira desigual.

Segundo Silva (1995) o conceito de capital cultural foi uma denominação feita por Pierre Bourdieu para analisar as situações de classes sociais. Diante disso, para ele

[...] o capital cultural é mais do que uma subcultura de classe; é tido como um recurso de poder que equivale e se destaca - no duplo sentido de se separar e de ter uma relevância especial - de outros recursos, especialmente, e tendo como referência básica, os recursos econômicos. Daí o termo capital associado ao termo cultura; uma analogia ao poder e ao aspecto utilitário relacionado à posse de determinadas informações, aos gostos e atividades culturais (SILVA, 1995, p.24).

Segundo as ideias de Pierre Bourdieu, o capital cultural pode se apresentar sobre três estados distintos: capital incorporado, objetivado e institucionalizado e a escola deveria ser capaz de reconhecer e considerar o capital cultural dos alunos das camadas "baixas" para que ocorra a democratização do ensino e a permanência nos estudos. (CARVALHO, 2012).

De acordo com Carvalho (2012, p.5), o capital incorporado é o "[...] reflexo do convívio familiar na construção do capital cultural do aluno". Já o capital objetivado se refere às condições que o aluno possui em apropriar-se de determinados privilégios. Dessa forma, o autor afirma que este capital é resultado das condições fornecidas pelo capital cultural objetivado. Em relação ao capital institucionalizado o autor direciona-o ao papel da escola enquanto mediadora do processo de transmissão do capital cultural, por meio dos diplomas.

Na visão de Tertuliano (2010, p.45), no capital incorporado “[...] a família desempenha papel fundamental pelo fato de a transmissão desse capital estar diretamente ligada ao que está incorporado em seu conjunto [...]." Em relação ao capital objetivado, o autor afirma que "[..] quando em suportes materiais, é transmissível em sua materialidade, sendo irredutível quanto ao que os agentes poderão dele se apropriar.” Do ponto de vista do capital institucionalizado, o autor 
afirma ainda que "[...] sob a forma de diploma, neutraliza propriedades oriundas do fato de ter os limites biológicos de seu suporte.”

Compreende-se dessa forma que o capital cultural dá forma, caracteriza e define as classes sociais que possuem estilos de vida próprios, consequentemente tais características vão diferenciando uma classe da outra. No que tange à educação, observa-se que há diferentes grupos culturais e sociais dentro de um mesmo ambiente escolar em que o papel dos recursos e capacidades estratégicas das famílias podem ser favoráveis ao êxito escolar (TERTULIANO, 2010), mesmo em meios populares.

As desigualdades sociais, portanto, se fazem muito presentes nas camadas populares torando mais difícil a prática de uma educação popular. Na visão de Carvalho (2015, p.11), uma educação popular considera que "[...] o processo de ensino que demanda uma didática diferenciada, por ser direcionado a uma parcela da população afligida por problemas e privações diversas [...].”, como é o caso típico de pessoas que estudam na EJA.

Sobre esse contexto, Carvalho (2015, p.11) destaca ainda que

Quando abordamos o termo camadas populares automaticamente relacionamos com a classe social na qual o sujeito está inserido, o termo dirige-se a todas as camadas da população, porém com atenção especial aquelas que sofrem carência de bens, informações ou poderes legitimados.

No entanto, é importante compreender que a heterogeneidade do público da EJA pode servir como instrumento de troca de saberes. Segundo Maciel (2011), Paulo Freire compreendia as classes populares como detentoras de um saber não valorizado e excluídas do conhecimento historicamente acumulado pela sociedade. Nesse viés, entende-se que o capital cultural tem uma parcela de contribuição significativa no processo de ensino-aprendizagem dos educandos, se bem compreendido pelos professores que trabalham na EJA.

Por sua vez, Maciel (2011, p.333) afirma que a relação "educação e cultura aparecem como importantes instrumentos de transformação social", logo, infere-se que estas são indissociáveis e essenciais para o processo de aprendizagem. No entanto, sob a perspectiva de um contexto neoliberal vê-se que diferentes classes sociais desenvolvem diferentes características de acordo com a sua trajetória social e é nesse parâmetro que se concentram as desigualdades e se manifestam os estigmas e preconceitos, assim como as possibilidades de superação.

Sem dúvidas, o capital cultural é de suma importância para o favorecimento do processo de escolarização, que por sua vez traz benefícios específicos a cada indivíduo, e dependendo de seu 
pertencimento social este recurso pode direcionar as pessoas a diferentes objetivos na vida, alterando suas percepções. Dessa forma, o aluno que tardiamente volta a estudar traz consigo muitas perspectivas quanto à escolarização e obviamente é dotado de um capital cultural carregado de experiências e vivências, ainda mais rico.

Sob o aspecto educacional do aluno que está retornando ao ambiente escolar, vale destacar que as trajetórias familiares servirão como norte para guiá-lo em seu processo de ensinoaprendizagem. Isso se verificou na pesquisa empírica. No entanto, não necessariamente será a única forma que estimulará esse aluno a prosseguir seus estudos, existe aí a emancipação cultural que os impulsiona a querer alcançar seus sonhos e ter a oportunidade que seus familiares não tiveram.

É notório que os indivíduos das camadas populares são os que mais sofrem com as desigualdades e mazelas sociais, ainda mais quando se tem padrões e culturas predominantes que se intitulam "legítimas". Contudo, conforme Amazonas et al. (2003, p.13)

[...] embora orientadas pelos ideais sociais vigentes em nossa época, terminam por fazer tentativas de conciliá-los com sua realidade de vida e [...] ainda que sofram a influência dos valores transmitidos pelas demais camadas da população, diferem significativamente delas, pois necessitam desenvolver estratégias de sobrevivência compatíveis com suas condições de existência.

Ou seja, mesmo que padrões sejam estabelecidos é necessário que as identidades sejam assumidas e afirmadas para que toda sociedade civil faça uso de seus direitos, assim toda herança cultural adquirida possa ser utilizada em favor do conhecimento e do crescimento intelectual dos indivíduos.

\section{PERCEPÇÃO DOS INDIVÍDUOS DAS CAMADAS POPULARES}

O estudo sobre percepções de alunos auxilia na análise dos significados e importância que estes dão à escola, trabalho e educação e, a partir disso compreender a relação que cada segmento tem com o processo de ensino-aprendizagem. Na visão de Camargo e Martinelli (2006, p.206) “[...] o estudo das percepções dos indivíduos [...] seria a maneira mais direta de se conseguir informações sobre sentimentos, valores e expectativas dos mesmos."

A percepção funciona como uma ferramenta para a interpretação da realidade, e no que se refere ao aspecto educacional auxilia, por exemplo, na compreensão da relação aluno-escola, advinda, principalmente, das experiências vivenciadas no cotidiano escolar.

Segundo Bacha, Strehlau e Romano (2006, p.6) 
A percepção é um fenômeno complexo que resulta de um conjunto de processamentos psicológicos humanos que envolvem tanto as sensações como pelo repertório do indivíduo presente na memória ou ainda associações e comparações.

Historicamente é possível observar o cenário de exclusão do sistema educacional, principalmente, das camadas populares. Nesse sentido, para Carvalho $(2015$, p.18) "é notório que as famílias de camadas populares não conseguem usufruir em sua plenitude dos benefícios que a elas é disponibilizado, por motivos diversos como a ausência de condições materiais, culturais e temporais."

Além disso, vale destacar a importância de se analisar características específicas desses sujeitos, como suas trajetórias sociais e escolares, para então compreender as razões pelas quais foram levados a parar e voltar a estudar e a partir disso investigar suas expectativas sobre a conclusão da educação básica.

Segundo Nienchoter e Steindel, (2013, p.17)

[...] o acesso de muitos sujeitos das classes populares à escola tem se realizado em um cenário cheio de percalços e suas trajetórias escolares são notoriamente marcadas por interrupções nos estudos, normalmente para cumprirem suas demandas econômicas. Esta questão, somada a outras intrínsecas aos processos educativos, tem levado então à exclusão de muitos jovens e adultos da escola regular.

Complementam dizendo ainda que "motivados por inúmeras questões, dentre elas as exigências capitalistas do mercado de trabalho, o retorno desses sujeitos à escola tem sido por meio de outra modalidade de ensino: a Educação de Jovens e Adultos." Nesse sentido, vê-se que o abandono às salas de aula sempre tem um porquê muito particular e que estigmatizados pela sociedade são vistos como quem não quer nada com a vida.

Dessa forma, é perceptível visualizar o que Pierre Bourdieu denominou de violência simbólica, uma violência não física, mas que é nutrida por todo preconceitos e estigmas. Aguiar (2005, p.10) afirma que conforme as ideias de Pierre Bourdieu e Passeron

[...] o princípio da violência simbólica consiste no reconhecimento - por parte de quem a comete, e até mesmo por parte de quem a sofre - da legitimidade de suas ações e consequências.

O autor diz ainda que "[...] trata-se também de uma violência silenciosa, porém perversa, que é cometida historicamente contra os mais pobres deste país: a negação dos direitos mais elementares, como saúde, educação, trabalho, segurança." Diante disso, é notório que esses indivíduos percebem o quanto é desafiador, em meio a tantos percalços, superar esses preconceitos e seguir na luta em favor de seus direitos básicos. 
Embora a violência simbólica seja difícil de ser percebida é essencial dar voz a esses personagens da educação, aos sujeitos da EJA, entender como cada indivíduo percebe o ensino que está sendo proposto e quais as dificuldades que enfrentam para estar em sala de aula, seja através de suas trajetórias sociais e escolares, sejam por questionamentos e indagações ou simplesmente suas perspectivas de vida, uma vez que cada sujeito possui suas particularidades na forma de pensar e agir.

\section{ALUNOS DA EJA: DESIGUALDADES SÓCIO EDUCACIONAIS E PERCEPÇÃO DE ALUNOS DA EJA SOBRE A ESCOLA - ACHADOS DE CAMPO}

Para cumprir o objetivo da pesquisa buscou-se características sobre o perfil dos sujeitos investigados no que tange à idade, origem, trabalho, recurso financeiro, família, cotidiano escolar, dificuldades educacionais pessoais e a própria percepção quanto à estrutura funcional dessa modalidade. Não se pode esquecer que a realidade investigada é situada na região Norte, na Amazônia amapaense.

Os dados constataram que os alunos entrevistados possuem diferentes perfis, características, histórias e trajetórias de vida que, de um modo geral, dificultam a permanência deles na escola. Também seus "estoques" de capital cultural é um importante componente que altera as percepções dos investigados conforme a quantidade e qualidade desse recurso que eles acessam e carregam consigo.

Fizeram parte do estudo 70 estudantes da EJA da $2^{a}$ etapa do ensino médio ( $2^{\circ}$ EJAM), correspondente ao $2^{\circ}$ e $3^{\circ}$ do Ensino Médio, de uma escola pública da cidade de Macapá, capital do Estado do Amapá/AP, localizado na região amazônica na parte setentrional. A faixa etária varia de 17 aos 56 anos. Nesse quesito, constatou-se que 79\% dos participantes eram jovens entre 17 a 23 anos de idade, conforme o gráfico abaixo: 


\section{GRÁFICO 01. FAIXA ETÁRIA DOS ESTUDANTES}

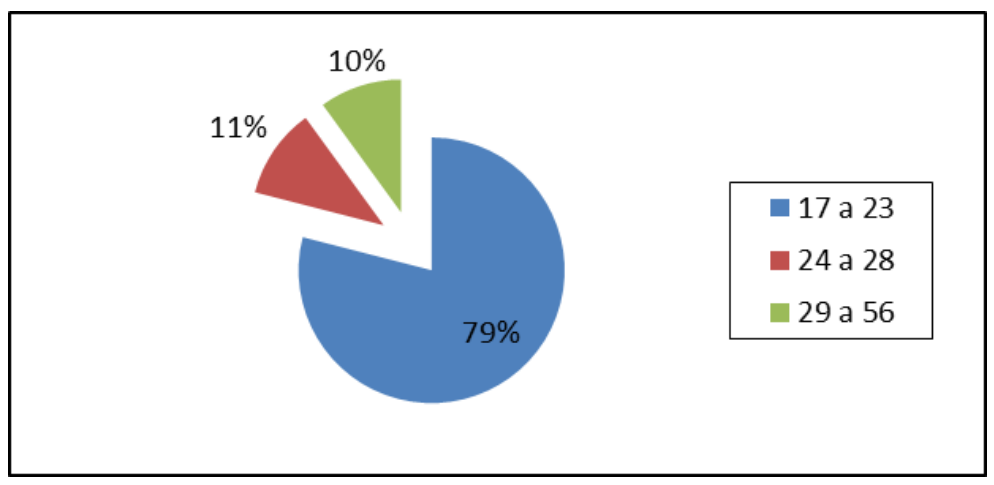

Fonte: Estudantes participantes do estudo.

Sobre a origem desse alunado, f em sua maioria são da própria cidade de Macapá (58\%), e do Estado do Pará (33\%), os demais de outras localidades da região Norte. Dentro desse contexto, pode-se observar que são, ainda assim, turmas heterogêneas e esse fator, somado às particularidades de cada indivíduo, lhes proporcionam uma bagagem cultural bem diferenciada. Entretanto, pode-se afirmar com base neste dado que todos eles fazem parte da matriz sócio cultural da própria Amazônia, isto é, eles são herdeiros da própria região de um tipo de extrato social que ficou conhecido na literatura específica como "campesinato caboclo".

Em relação às atividades produtivas, foi perguntado se os alunos trabalhavam ou não com carteira assinada. Notou-se que $80 \%$ dos alunos estão inseridos no mercado de trabalho, seja ele formal ou informal e que apenas $11 \%$ trabalha com carteira assinada variando a média salarial.

De acordo com Costa et al (2007, p.67)

Sem a escolaridade mínima exigida e uma qualificação profissional adequada para concorrer no mercado cada vez mais seletivo, grande parte desse contingente é direcionada à informalidade, trabalha sem registro na carteira e sem perspectiva de ser amparado pela seguridade social e engrossa as estatísticas oficiais.

Analisando os resultados sobre o trabalho, pode-se inferir que cada vez mais cedo o adolescente e o jovem estão começando a trabalhar, logo, de acordo com Pierro, Joia e Ribeiro (2001, p.64) "a entrada precoce dos adolescentes das camadas mais pobres no mercado de trabalho formal ou informal provocou a sua transferência para os programas de educação originalmente destinados à população adulta.”

Vale destacar ainda as ideias de Costa et al (2007, p.65) que afirmam que "o trabalho precoce na vida desses alunos interfere significativamente no desempenho escolar, além de lhes atribuir a árdua tarefa de contribuir com o orçamento familiar, cerceando o pleno desenvolvimento físico, mental, social [...]”. 
Por seu turno, Aguiar (2005, p.4) enfatiza que

[...] esses jovens e adultos são duplamente punidos: não apenas por encontrarem-se na situação de maior vulnerabilidade diante dos problemas estruturais que assolam os mais pobres deste país, como também por serem alvos de políticas menores que, apesar de pretenderem contribuir para relações de maior igualdade, reduzem-se a práticas assistencialistas quer e forçam estigmas e desigualdades nas quais os jovens e adultos, em vez de serem vistos como sujeitos de direito, iguais, tornam-se objeto de compaixão, o que se revela como uma violência a mais cometida contra este público.

Somando-se a entrada precoce no mercado de trabalho, tem se ainda os jovens que tão cedo formam famílias e acabam se dedicando ao lar. Foi questionado aos participantes se tinham ou não companheiros onde se constatou que $63 \%$ não possuíam, entretanto, um número considerado significativo respondeu que $\operatorname{sim}(34 \%)$.

Foi questionado também se os alunos tinham filhos ou não e $60 \%$ respondeu que não tinham e 37\% sim, número também que pode ser considerado razoável. Dos sujeitos que responderam ter filhos, $58 \%$ possui apenas um filho, $19 \%$ possui dois filhos e $23 \%$ possui mais de 3 filhos. Esse condicionante em muitos casos pode ser um fator decisivo para o abandono aos estudos, uma vez que pressiona o indivíduo ou sua família de origem.

Observou-se que apesar de um número significativo já estar inserido no mercado de trabalho, ou mesmo já possuir sua própria família, não possuem uma estrutura financeira independente. Dado esse revelado pela percentagem de indivíduos que moram com os pais (61\%). Este dado revela que possivelmente passa a existir uma pressão maior sobre a família original e nuclear que pode se tornar uma família extensa, ou, ainda mais extensa.

A estrutura familiar é, quase sempre, uma das responsáveis pelo suporte do aluno no âmbito escolar, logo, se a família enfrenta dificuldades estruturais e sociais isso pode implicar diretamente no desenvolvimento educacional deste sujeito. Dentro desse contexto, observou-se que as famílias dos alunos são de classes populares, simples e com baixa renda salarial.

Quanto ao contexto estrutural, são famílias que moram em casas de madeira (56\%), alvenaria (30\%) e mista (11\%), sendo constituídas por um número significativo de moradores em uma mesma casa e em bairro periféricos com quase nenhuma infraestrutura ou equipamento social disponível. São famílias de 1 a 3 pessoas, (26\%), 4 a 6 pessoas (43\%), 7 a 15 pessoas (31\%).

No que se refere à trajetória escolar dos pais, pode-se perceber que houve um rompimento muito cedo com os estudos. Os dados revelaram que os pais em sua maioria possuem o ensino fundamental incompleto (34\%), ensino fundamental completo (13\%), ensino médio incompleto 
(6\%), ensino médio completo (13\%), apenas $1 \%$ com ensino superior completo e $3 \%$ nunca estudaram. Vale destacar que $30 \%$ não respondeu a esse questionamento.

Em relação à escolaridade das mães, os dados mostraram que $27 \%$ possuíam ensino fundamental incompleto, $14 \%$ fundamental completo, $6 \%$ ensino médio incompleto, $23 \%$ médio completo, $4 \%$ também frequentaram a EJA, ou seja, tardiamente começaram ou voltaram a estudar, $7 \%$ ensino superior completo, $3 \%$ nunca frequentou a escola e $16 \%$ não responderam a esse questionamento.

Entre as ocupações citadas dos pais, destaca-se que em sua maioria são carpinteiros, pedreiros, mestre de obras, autônomos, vigilantes, vendedores, agricultores, comerciantes, entre outros, mas quase sempre ocupações de baixo status social. Já em relação à ocupação das mães, destaca-se dona de casa, domésticas, costureiras, autônomas, comerciantes, agricultoras, segurança, entre outras. Vale destacar que foi observado ainda pedagogas, contabilistas, secretárias e professoras que pode se aferir ser devido à maior escolaridade, ainda que em pequeno número.

No entanto, apesar de pouca estrutura, o exemplo familiar e trajetórias escolares de sucesso vão delineando caminhos positivos e não só pai e mãe viram possibilidades para esses estudantes, mas outros familiares também se dispõem a ajudar ou tornam-se referencias desses alunos da EJA. Nesta pesquisa, por exemplo, foi observado um número considerável de indivíduos com nível superior na mesma residência (43\%), apontados pelos alunos como sendo seus irmãos, tios, primos, e, em menor número os próprios pais.

Sobre a caracterização da vida de estudante foi indagado se faltavam à escola, se acreditavam que iriam cursar o ensino superior, se tinham apoio da família nos estudos e se em algum momento já tiveram que parar de estudar. Todos os questionamentos acima citados vieram seguidos de seus respectivos motivos. Aqui a categoria percepção foi muito útil no cumprimento dos objetivos da pesquisa.

Em relação a ausência na sala de aula, 53\% afirmaram faltar raramente, 11\% afirmaram faltar e 36\% afirmou não faltar. Dos que afirmaram faltar ou faltar raramente, as razões que se repetiram são por consequência do trabalho, problemas de saúde, cuidar da casa e dificuldades de locomoção (sem dinheiro para transporte).

Dos que afirmaram não faltar o que se destacou foi a preocupação com conteúdo perdido, não trabalham e por isso não tem tantas outras ocupações. Além disso, tem os sujeitos que deixam evidente que não faltam pois querem recuperar o tempo perdido que ficaram fora de sala de aula. 
Carbone (2013, p.16) afirma que "são realidades distintas a cada aluno, pois vivem num mundo de trabalho, família, grupos, são responsabilidades tantos sociais quanto familiares, com valores morais e éticos criados a partir da experiência pessoal [...].” Nesse sentido, percebe-se que mesmo com suas dificuldades e individualidades eles procuram estar presentes nas aulas.

Ao serem questionados sobre a perspectiva de cursar ou não o ensino superior, $93 \%$ acredita que sim, 6\% dificilmente e $1 \%$ acredita que não. Dos que responderam sim, destacam-se três respostas (alunos identificados com siglas para preservar suas identidades) que chamam a atenção quanto aos motivos:

"Creio que sim, pois a cada dia que passa o mercado de trabalho fica mais disputado, quanto mais me qualificar melhor". (A1).

"Acredito que sim, pois as condições e necessidades que vivo me motiva para buscar sempre o melhor para mim e minha família”. (A2).

“Acredito que todos têm capacidades para cursar um nível superior, só depende de nós”. (A3)

Em relação aos que não acreditam ou dificilmente irão cursar o ensino superior, destaca-se duas respostas:

"Dificilmente porque trabalho e é difícil conciliar estudo e trabalho". (B1).

"Não, porque não tenho como pagar uma faculdade". (B2).

Sobre esse contexto, Carbone (2013, p.17) afirma que

Muitas vezes os alunos vêm para a escola com problemas, oprimido, baixa autoestima, por vezes pela condição de excluído, de retardatário, que chega a escola cansado, e diante de uma situação nova, e diferente, sente-se oprimido e desestimulados a acreditar que são capazes.

Em relação ao apoio familiar, 91\% respondeu que a família colabora e apoia em seus estudos, 7\% disseram não (uns devido a família morar longe e outros por nunca terem tido apoio nos estudos) e $2 \%$ raramente dá apoio. Dos que responderam ter apoio, tem-se alguns fragmentos:

"Sempre, para que eu tenha uma boa estrutura e uma vida financeira melhor". C1.

"Eles depositam a confiança deles em mim, acreditam que posso alcançar e realizar aquilo que eles não conseguiram e tenho força de vontade”. C2.

"Sabem que é o melhor caminho e é uma forma de viver melhor, não muito em ter dinheiro, mas conhecimentos das coisas do mundo". C3.

No que se refere ao abandono escolar, foi constatado que $63 \%$ já tiveram que parar de estudar, sendo que $34 \%$ já abandonaram pelo menos uma vez, e $32 \%$ mais de duas vezes. 
TABELA 01. ABANDONO ESCOLAR

\begin{tabular}{l|l|l|l}
\hline \multicolumn{1}{l|}{ Teve que parar de estudar alguma vez? } & \multicolumn{2}{l}{ Quantas vezes? } \\
\hline \multirow{2}{*}{ SIM } & \multirow{2}{*}{$63 \%$} & 1 vez & $34 \%$ \\
\cline { 3 - 4 } & & 2 vezes & $34 \%$ \\
\cline { 3 - 4 } & & 3 vezes & $27 \%$ \\
\cline { 3 - 4 } & & 4 vezes & $5 \%$ \\
\hline NÃO & $37 \%$ & - & \\
\hline
\end{tabular}

Fonte: pesquisa de campo

Os motivos do abandono são os mais variados, entre eles: trabalho, gravidez, viagem (mudança de cidade), problemas familiares e de más companhias. Dos que afirmaram não ter parado de estudar, $37 \%$, responderam não ter parado devido nunca ter tido motivos para tal.

No tocante aos conteúdos e disciplinas ofertadas foi questionado sobre quais as duas disciplinas que o aluno tinha maior dificuldade e melhor facilidade em aprender. Os dados revelaram que Matemática e Química são as disciplinas que eles mais apresentaram dificuldades e História, Geografia e Português (Geografia e Português tiveram o mesmo percentual) são as disciplinas que mais apresentaram facilidades.

Diante dos dados obtidos, notou-se que esses estudantes apresentam dificuldades com cálculos, pois, aparentemente, exigem mais atenção e dedicação devido sua complexidade. Eles responderam que não tem tempo para revisar conteúdo ou resolver exercícios extraclasse e por isso não se familiarizam com os conteúdos. Nenhum dos alunos questionou a capacidade técnica, didática ou metodológica dos professores que ministram as disciplinas que consideram mais difíceis. Contudo, sobre as disciplinas com mais facilidades foi possível notar a importância do professor, pois destacaram a excelência no trabalho ministrado.

Em relação ao capital cultural do aluno foi questionado quanto aos lugares frequentados por eles e quais as programações de televisão preferidos. Os dados mostraram que em sua maioria eles não frequentam com assiduidade cinemas, clubes e festas ou confraternizações, até porque não dispõem de dinheiro para isso. No entanto, em relação a igreja, 61\% participam ativamente, $27 \%$ participam raramente e $11 \%$ não participam. Nesse caso, as atividades realizadas pela igreja também se tornam fontes de lazer para esses alunos.

Em relação ao cinema, apenas $24 \%$ responderam que costumam frequentar. Em contrapartida $43 \%$ afirmaram que não frequentam e $33 \%$ afirmaram ir raramente. Em relação à clubes e festas, notou-se um grupo bem equilibrado quanto as respostas, pois $37 \%$ respondeu que sim, $43 \%$ respondeu não frequentar e $20 \%$ disse que frequenta, mas raramente. Sobre confraternizações foi possível notar que $30 \%$ costuma ir, $39 \%$ não frequenta e $31 \%$ frequentam 
raramente. Necessário destacar, considerando as variáveis contextuais, que essas formas de lazer estão adstritas a estrutura social e comunitária onde essas pessoas vivem.

Em muitos casos a não frequência a locais como cinemas e shopping centers se deve ao poder aquisitivo das famílias investigadas, pois como são de camadas populares, é possível inferir que o seu lazer é limitado pelas condições econômicas a que estão sujeitas.

No entanto, apesar das categorias cinema, clubes e festas e confraternizações terem registrado baixos percentuais é relevante enfatizar que esses estudantes, especialmente os mais jovens, não abrem mão de seu lazer participando de encontros e festas em seus próprios bairros mesmo que nestes bairros não haja equipamentos sociais que permitam diversão, ou diversão segura.

Sobre as duas programações de televisão preferidas pelos investigados os dados revelaram que jornais e filmes são as duas programações que eles mais assistem seguidas de esportes, novelas e programas de auditórios respectivamente.

A categoria conceitual capital cultural aqui torna-se um fator revelador que explica as percepções dos alunos ao relacionarem a escola aos seus costumes e consequentemente suas expectativas. E apesar de serem mais hábeis com um tipo de saber não formal, vindo de berço, a escola para eles é essencial no desenvolvimento de saberes científicos e culturais.

Por fim, um dos pontos mais relevantes da pesquisa foi quanto às suas rotinas de vida: foi possível diagnosticar as dificuldades que enfrentam para estar de volta aos bancos escolares, as expectativas sobre a escola e o ensino que lhes é ofertado e as expectativas quanto ao acesso em um nível superior.

Diante disso, muito além de identificar quem são os alunos da EJA, é de suma importância aprofundar as análises sobre seu perfil procurando compreendê-lo através de suas trajetórias de vida, do seu dia-a-dia e o que explica muitas vezes a falta de atenção na sala de aula, o baixo rendimento, os atrasos, as faltas, o não cumprimento das atividades extraclasses e até mesmo as desistências de estudar.

Dos estudantes que já haviam afirmado estar trabalhando, notou-se uma rotina corriqueira e cansativa. Além disso, trabalhos exaustivos realizados nos dois turnos, manhã e tarde, o que dificulta o cumprimento de tarefas extraclasses e revisão de conteúdos. Conforme mencionado por eles:

“Acordo 6h da manhã para me arrumar para ir trabalhar, as 7h já estou na parada, meu horário é as $8 \mathrm{~h}$ da manhã até as $17 \mathrm{~h}$ da tarde, quando chego em casa, por volta das $17 \mathrm{~h} 50$ vou tomar 
banho e me arrumar e as $18 \mathrm{~h} 15$ venho pra escola. Chego em casa as 23:30 e durmo por volta de meia noite. No outro dia a mesma rotina". C1

“Acordo às 7h, trabalho o dia todo. À noite, vou para a escola, todo dia chego atrasado, fico a aula inteira com muito sono, cansado do dia todo trabalhando, muitas vezes isso acaba me prejudicando [...]". C2.

“Acordo 6h30 para trabalhar, eu não tenho muito tempo para pegar no caderno para estudar e fazer os trabalhos que os professores passam quando eu chego do trabalho". C3.

O que parece explicar, na maioria dos casos, o não cumprimento das tarefas, os atrasos e faltas à escola é o cansaço do trabalho, pois a maioria trabalha o dia todo, portanto, o tempo de descanso é a hora do almoço e o outro tempo livre usam para ir à escola. Em outros casos, por trabalharem na informalidade notou-se que os horários avançam noite a dentro o que os impede de chegar a tempo no horário da aula.

A rotina dos respondentes que não estão no mercado de trabalho também se mostrou bem movimentada, uma vez que se identificou um número significativo de donas de casa, assim como jovens que ajudam nas tarefas de casa e cuidam dos irmãos mais novos.

"Acordo 8h, não trabalho, mas cuido dos filhos e dos meus animais. Espero cursar um nível superior e espero que a escola seja uma das escadas que terei que subir”. D1.

"Eu acordo 7h30 da manhã, tomo café da manhã, em seguida vou fazer minhas tarefas de casa, cozinhar, lavar roupa, limpar casa e a tarde tiro tempo para ler livros, jornais e estudar um pouco, a noite venho pra escola, chego em casa e tomo banho, assim que eu concluir o ensino médio pretendo cursar pedagogia”. D2.

"De manhã faço cursinho, de tarde cuido da minha irmã de 4 anos e cuido das tarefas de casa. Â noite estudo, como chego atrasada procuro sentar na frente para prestar atenção nas aulas. Quando chego em casa, chego cansada e tomo banho pra dormir". D3.

Para o aluno que volta a estudar já adulto é fundamental ter o apoio e solidariedade da família, assim como da escola, para que se tenha maiores chances de concluir com êxito os estudos, pois em muitos casos, no primeiro obstáculo que enfrentam as possibilidades de abandono são reais e altíssimas.

Diante dos dados levantados, dos 7\% que responderam não ter apoio familiar foi possível detectar que alguns desses alunos depositam toda carga de responsabilidade em si próprios ao afirmarem que "Só depende de mim e de mais ninguém para que eu seja algo na vida" D4. Acredita-se que a força de vontade, aliado ao apoio da escola e ao desejo de concluir os estudos deva ser um forte aliado para que seus desejos se concretizem. 


\section{APROXIMAÇÕES CONCLUSIVAS}

O objetivo foi analisar a EJA sob o olhar do aluno, caracterizando-o, em uma perspectiva ampla e concreta, onde se pudesse contextualizar a vivência desse aluno na escola, relacionando-a com seu cotidiano, com sua trajetória escolar e familiar. São percepções singulares que deram sentido aos problemas que são visualizados, julgados e não compreendidos pela sociedade.

A EJA é permeada por estigmas e preconceitos que se direcionam ao público advindo das camadas populares que são os sujeitos com poder aquisitivo baixo e que por várias razões não tiveram acesso ao ensino de modo regular. Diante disso, coube aqui analisar e contextualizar a categoria capital cultural, já que se trata de uma modalidade de ensino que insere indivíduos com muitos saberes e vivências.

As evidencias mostraram que são alunos em sua maioria do próprio Estado do Amapá, com baixa renda e com grande quantidade de pessoas morando em uma mesma residência. Em aspectos estruturais, possuem trajetórias familiares semelhantes onde os pais possuem baixa escolaridade e também, na maioria dos casos, seus ascendentes sempre trabalharam na informalidade.

Para alguns indivíduos do público da EJA, em suas particularidades, a concepção de vida e expectativa escolar depende, essencialmente, de seu esforço individual para obter êxito, ou seja, muitos acreditam que somente eles são os responsáveis pelo seu sucesso ou fracasso. Praticamente não surgiu críticas aos professores ou a escola onde estudam.

Por outro lado, foi possível constatar também que para a maioria deles o término dos estudos significa muito mais que melhoria de vida, mas sim uma forma de mostrar para eles mesmos que são capazes de realizar seus sonhos e isso faz retomar sua autoestima e ânimo para viver. Para tanto contam com apoio familiar e se apoiam nos estudos para concretizar seus sonhos.

Os investigados que estão inseridos no mercado de trabalho, principalmente, os da informalidade, procuram a melhoria na qualidade de vida, estrutural e financeira, pois muitos são os responsáveis pela renda familiar e distantes da escola há muito tempo buscam a ascensão profissional por meio dos estudos.

Todos, são sujeitos que apresentam dificuldades financeiras e de aprendizagem, em decorrência de uma etapa da vida que parou no tempo e que lhes impediu de continuar uma vez, duas vezes, três vezes e até quatro vezes seus estudos. Ainda assim, eles retornam aos bancos escolares. 
Sobre suas percepções, são motivados pela busca na melhoria de vida e ascensão profissional, mas também pela crença em suas potencialidades e objetivos de vida. A maioria acredita que vai chegar ao ensino superior ainda que não tenham explicado como ou justificado essas respostas.

A EJA é uma política pública que veio quebrar paradigmas, ao que parece, porque é uma educação voltada para a camada mais baixa e excluída, no entanto, devemos estar atentos para qualidade do que está sendo ofertado e levar em consideração as particularidades desse alunado.

Confirmou-se que esse aluno ao voltar para a escola, já adulto, traz consigo o cansaço do trabalho, o preconceito por estar estudando determinada série com idade "distorcida", dificuldades de aprendizagem, como no caso das disciplinas com cálculos, por eles mencionadas.

Nesse sentido, todas as dificuldades apresentadas pelos alunos devem ser levadas em consideração pelos educadores que trabalham nessa modalidade de ensino para que assim os índices de evasão ou mesmo perda de interesse nos estudos não venha a desmotiva-los e mais uma vez o abandono seja a saída mais fácil para eles.

É válido destacar que é necessário se ter o apoio material e financeiro tanto para docentes como para discentes na modalidade EJA, pois nada funciona apenas com boa vontade e sim com materialidade e eficácia. Logo, dar condições para o acesso e permanência desses alunos é essencial para motiva-los a não desistir. Infelizmente no Brasil não se tem incentivos ao ensino de qualidade, muito menos a modalidade EJA, o que se tem são falsas promessas de melhorias, ou mesmo programas de atendimento a esse público alvo específico, mas que são políticas isoladas.

Aquele que por várias razões deixou de estudar não o fez de modo gracioso. A culpa não é do aluno, ele precisou trabalhar para sustentar sua família e vem de uma herança familiar com estoques de capital cultural tidos como "não legítimos". É necessário a formulação de políticas públicas educacionais que dê a modalidade EJA a sua devida importância. 


\section{REFERÊNCIAS}

AGUIAR, Alexandre da Silva. Alfabetização de jovens e adultos no contexto das desigualdades sociais e da violência estrutural brasileira: O Programa Brasil Alfabetizado no Estado do Piauí. Dissertação (Mestrado em Educação).2005. 82f. Universidade Federal Fluminense, Faculdade de Educação, Niterói-RJ. 2005.

AMAZONAS, Maria Cristina Lopes de Almeida et al. Arranjos familiares de crianças das camadas populares. Revista Psicologia em Estudo, Maringá,v. 8, num. esp., p. 11-20, 2003. Disponível em: http://www.scielo.br/pdf/pe/v8nspe/v8nesa03.pdf>. Acesso em: 27 de nov.2016 às $15 \mathrm{~h}$ e $02 \mathrm{~min}$.

BACHA, Maria de Lourdes; STREHLAU, Vivian Iara; ROMANO, Ricardo. Percepção: termo freqüente, usos inconseqüentes em pesquisa? In 30 Encontro da ANPAD, 2327 de setembro de 2006 -Salvador- BA-Brasil. Disponível em: < http://www.anpad.org.br/enanpad/2006/dwn/enanpad2006-mkta-1332.pdf >. Acesso em: 16 de set.2016 às $17 \mathrm{~h}$ e $05 \mathrm{~min}$.

BEISIEGEL, Celso de Rui. Considerações sobre a política da União para a Educação de Jovens e Adultos analfabetos. Revista Brasileira de Educação. Trabalho apresentado na XIX Reunião Anual da ANPEd, Caxambu, setembro de $1996 . \quad$ Disponível em: <http://anped.tempsite.ws/novo_portal/rbe/rbedigital/RBDE04/RBDE04_04_CELSO_DE_RUI_BEISIEGEL.pdf>.

Acesso em: 12 de set.2016 às $19 \mathrm{~h}$ e $53 \mathrm{~min}$.

BONETI, Lindomar Wessler. As políticas públicas no contexto do capitalismo globalizado: da razão moderna à insurgência de processos e agentes sociais novos. PRACS: Revista Eletrônica de Humanidades do Curso de Ciências Sociais da UNIFAP.ISSN 1984-4352 Macapá, n. 5, p. 17-28, dez. 2012. Disponível em: <file:///C:/Users/User/Downloads/587-2221-1-PB.pdf>. Acesso em: 25 de jul.2016 as 23h e 33min.

BRASIL. Lei de Diretrizes e Bases da Educação Nacional. Lei número 9394, 20/12/1996. Disponívelem:<http://www.planalto.gov.br/ccivil_03/leis/L9394.htm>Acesso em: 25 de jul.2016 às 23h e 15min.

CAMARGO, Poliana da Silva Almeida Santos; MARTINELLI, Selma de Cássia.Educação de adultos: percepções sobre o processo ensino-aprendizagem. Revista Semestral da Associação Brasileira de Psicologia Escolar e Educacional (ABRAPEE) • Volume 10 Número 2 Julho/Dezembro 2006, p.197-209. Disponível em: <http://www.scielo.br/pdf/pee/v10n2/v10n2a04.pdf>. Acesso em: 15 de ago.2016 às $21 \mathrm{~h}$ e $22 \mathrm{~min}$.

CARBONE, Solange Aparecida Beletato. Dificuldades de aprendizagem na Educação de Jovens e Adultos: uma reflexão com alfabetizadores da EJA. Monografia (Especialização em Educação: Métodos e Técnicas de Ensino). 2013.39f. Universidade Tecnológica Federal do Paraná, Câmpus Medianeira, Madianeira-PR.2013

CARVALHO, Luciano de Souza. O Capital Cultural na construção de uma Educação Democrática, Reflexiva e Libertadora. Rev. Thema, v. 09; n.02. 2012. P.1-16 Disponível em: <http://revistathema.ifsul.edu.br/index.php/ thema/article/viewFile/144/83>. Acesso em:26 de out.2016 às $11 \mathrm{~h}$ e $14 \mathrm{~min}$.

CARVAlHO, Luciano de Souza; DIAS, Thanisa Kelly. Processo de escolarização nas camadas populares: os desafios familiares de pensar e cuidar da Educação básica dos filhos. 2015. 36f.Trabalho de Conclusão de Curso (Graduação em Pedagogia). Universidade Estadual da Paraíba, Centro de Educação, Campina Grande-PB, 2015.

COSTA, Clodoaldo Marques et al. A EJA e o aluno trabalhador: aspectos de uma difícil relação. Trabalho de Conclusão de Curso (Graduação em Pedagogia). 2007.119f. Universidade Federal do Amapá-UNIFAP, Macapá-AP. 2007.

DUARTE, Heloisa Helena Aparecida Chaves. O Olhar Filosófico de Paulo Freire sobre Alfabetização de Jovens e Adultos, 2012. 47 fls. Trabalho de Conclusão de Curso (Graduação em Pedagogia). Universidade Estadual de Londrina, Londrina,

2012.Disponívelem:<http://www.uel.br/ceca/pedagogia/pages/arquivos/HELOISA\%20HELENA\%20APARECIDA\%2 0CHAVES\%20DUARTE.pdf>. Acesso em: 14 de jul.2016 às $17 \mathrm{~h}$ e $25 \mathrm{~min}$.

GATTI, Bernardete A. Estudos quantitativos em educação. Educação e Pesquisa, São Paulo, v.30, n.1, p. 11-30, jan./abr. 2004. Disponível em: 〈http://www.scielo.br/pdf/ep/v30n1/a02v30n1.pdf>. Acesso em: 14 de jun.2016 as $17 \mathrm{~h}$ e $47 \mathrm{~min}$.

MACIEL, Karen de Fátima. O pensamento de Paulo Freire na trajetória da educação popular. Revista Educação em Perspectiva, Viçosa, v. 2, n. 2, p. 326-344, jul./dez. 2011. Universidade Federal do Estado do Rio de Janeiro. Disponível em: <http://www.seer.ufv.br/seer/educacaoemperspectiva/index.php/ppgeufv/article/viewFile/196/70> . Acesso em: 13 de jun.2016 às $17 \mathrm{~h}$ e $02 \mathrm{~min}$. 
NIENCHOTER, Rosane; STEINDEL, Gisela Eggert.Trajetórias sócio-escolares na Educação de Jovens e Adultos: uma leitura na perspectiva de Bernard Lahire. Revista Educ. Públ. Cuiabá,v.22; n.48; p.13-28. Jan/abr.2013. Disponível em: <file:///C:/Users/User/Downloads/845-1655-1-PB.pdf>. Acesso em: 25 de jul.2016 às $00 \mathrm{~h}$ e $45 \mathrm{~min}$.

OLIVEIRA, Aline Benedita Teixeira de; LIMA, Martha Barbosa; PINTO, Eliane Aparecida Toledo. Educação de Jovens e Adultos (EJA): Perspectivas Metodológicas e Aprendizagem Significativa. Mimesis, Bauru, v. 33, n. 2, p. 181-204, 2012. Disponível em: <http://www.usc.br/biblioteca/mimesis/mimesis v33 n2 2012 art 05.pdf $>$. Acesso em: 17 de jul.2016 às $15 \mathrm{~h}$ e $16 \mathrm{~min}$.

PIERRO, Maria clara Di; JOIA, Orlando; RIBEIRO,Vera Masagão. Visões da Educação de Jovens e Adultos no Brasil. Cadernos Cedes, ano XXI, no 55, novembro/2001. Disponível em: <http://www.scielo.br/pdf/ccedes/v21n55/5541.pdf>. Acesso em: 27 de set.2016 as 10h e 03min.

SILVA, Gilda Olinto do Valle. Capital cultural, classe e gênero em Bourdieu. INFORMARE - Cadernos do Programa de Pós-Graduação em Ciência da informação, v.1, n.2, p.24-36, jul./dez. 1995. Disponível em: <http://ridi.ibict.br/bitstream/123456789/215/1/OlintoSilvaINFORMAREv1n2.pdf>. Acesso em: 27 de out.2016 às 09h e $37 \mathrm{~min}$.

SOBRAL, Osvaldo José. Ensaio Sobre o Método de Pesquisa Marxista: uma perspectiva do materialismo dialético. Revista Científica FacMais, Volume. II, Número 1.Ano2012/2ºmestre.p.6-3.Disponívelem:<http:// revistacientifica.facmais.com.br/wp-content/uploads/2012/10/1.ENSAIO-SOBRE-O-M\%C3\%89TODO-DEPESQUISA-MARXISTA-Osvaldo-Jos\%C3\%A9-Sobrall.pdf>. Acesso em: 20 de abr. 2016.

TERTULIANO, Maria Jussara dos Santos. Famílias de camadas populares e escola: discursos e práticas na escolarização dos filhos. 2010.223f. Dissertação (Mestrado em Educação). Universidade Federal de São João Del-Rei, São João Del- Rei-MG. 2010. 


\section{RESUMO}

O objetivo é analisar o contexto da Educação de Jovens e Adultos (EJA) sob o olhar do aluno, a partir de suas percepções de escola e das dificuldades de aprendizagem analisando suas vivências e trajetórias de vida. Diálogos com os autores Oliveira; Lima e Pinto (2012), Carvalho (2015) e Carbone (2013), entre outros. Categorias conceituais como percepção, capital cultural e camadas populares foram centrais. A abordagem foi quali-quantitativa com análise de conteúdo e estatística. 70 alunos da EJA de uma escola pública foram os investigados. Dados apontam para alunos que veem na escola o melhor caminho para ascensão profissional; trajetórias escolares e dificuldades financeiras contribuíram a entrada nessa modalidade de ensino. Acreditam que vão cursar o ensino superior.

Palavras-chave: Capital Cultural. Educação de Jovens e Adultos. Percepção.

\section{ADULT EDUCATION (EJA): CULTURAL CAPITAL AND PERCEPTIONS ABOUT SCHOOL IN AMAZON AMAPAENSE \\ ABSTRACT}

The objective is to analyze the context of Youth and Adult Education (EJA) under the students' perspective, based on their perceptions of the school and the learning difficulties analyzing their experiences and life trajectories. Dialogues with the authors Oliveira; Lima and Pinto (2012), Carvalho (2015) and Carbone (2013), among others. Conceptual categories such as perception, cultural capital, and popular strata were central. The approach was qualitative-quantitative with content and statistical analysis. 70 students EJA from a public school were investigated. Data point to students who see in school the best way for professional advancement; School trajectories and financial difficulties contributed to the entrance in this modality of education. They believe that they will attend higher education.

Keywords: Cultural Capital. Youth and Adult Education. Perception. 